\title{
ARRUDA, Larissa Rodrigues Vacari de. Disputas oligárquicas: as práticas políticas das elites mato-grossenses (1892-1906). São Carlos: EdUFSCar, 2015. 206 páginas.
}

Alessandro Cavassin Alves ${ }^{1}$

- Enviado em 13/05/2017

- Aprovado em 28/06/2017

\section{Famílias políticas no Mato Grosso na Primeira República}

O livro Disputas oligárquicas: as práticas políticas das elites mato-grossenses (1892-1906) de Larissa Rodrigues Vacari de Arruda (EduFSCar, 2015) é fruto de sua dissertação de mestrado defendida no Programa de Pós-Graduação em Ciência Política da Universidade Federal de São Carlos (UFSCar), tendo como orientadora Profa. Dra. Maria Teresa Miceli Kerbauy e que, também, escreve o Prefácio da obra. Maria Teresa salienta que a autora "oferece uma importante contribuição para o entendimento das especificidades das práticas políticas regionais e das manifestações do poder privado e familístico durante o período da Primeira República e seus inúmeros conflitos relacionados aos temas candentes deste período: federalismo e autonomia regional" (Kerbauy, in: ARRUDA, 2015, p.09).

O poder privado e familístico estão fortemente representados no Mato Grosso do início da 1a República por dois indivíduos (atores políticos), Generoso Paes Leme de Souza Ponce (Generoso Ponce) e Joaquim Duarte Murtinho (Joaquim Murtinho) e suas famílias. Ambos formaram as bases para se entender a estrutura política local que engloba, assim, as demais famílias oligárquicas do

\footnotetext{
${ }^{1}$ Professor de Sociologia. Graduado em Ciências Sociais pela UFPR, Mestre e Doutor em Sociologia pela UFPR. E-mail: alessandrocavassin@gmail.com
} 
Mato Grosso, mas especificamente, outras duas, a Paes de Barros e a Corrêa da Costa. Serão essas quatro famílias as referências do poder político no Mato Grosso no período estudado.

Portanto, estudar esse Estado da federação, passa pelo entendimento das quatro famílias e suas estratégias para se manterem no poder, num misto de virtú e fortuna, como diria Maquiavel, por parte de seus líderes, mas também, não há como negar uma estrutura política específica que permite a esses sujeitos e suas famílias dominarem tão fortemente todo um período inicial da República no Mato Grosso. A autora utiliza o conceito de elites, enquanto grupos dominantes, para diferenciar esses poucos mato-grossenses à frente do poder local dos demais. E, aponta igualmente que essas bases do poder estão no caráter coronelista de mando, porém, sendo coronéis específicos, não exclusivamente rurais, pois Generoso Ponce é um rico comerciante em Cuiabá e Joaquim Murtinho é um famoso médico, político e empresário. Mas, não significa que não tenham relações com o latifúndio. E, pode-se observar que a família é um elemento estrutural que compõe o entendimento desse grupo.

E, compreender este delicado período de início da República no Brasil, de um federalismo que visava dar maior autonomia aos Estados, e a partir de um território tão amplo, isolado e fronteiriço (que atualmente forma os Estados de Mato Grosso, Mato Grosso do Sul e Rondônia), que necessita do apoio do governo central no Rio de Janeiro, sob a ação política de indivíduos específicos, líderes de seus grupos oligárquicos, de suas famílias, é uma grande contribuição da autora para a apreensão de como a política brasileira se dava, e enquanto possibilidade de um exercício de comparação com as outras unidades da federação, algo ainda em construção. A bibliografia regional centrada nos clássicos estudos de Joseph Love sobre São Paulo e Rio Grande do Sul, John Wirth sobre Minas Gerais e Roberto Levine, sobre a Bahia, entre muitos outros, amplia-se, agora, com o livro de Larissa Arruda. Destaca-se, também, a recente publicação sobre o mesmo período no Estado do Paraná, de Mônica Helena Harrich Silva Goulart (2014), que de forma profunda analisa os políticos da Assembleia Legislativa paranaense, seus coronéis e o seu poder executivo. Também Goulart identifica a liderança de indivíduos específicos, filhos de tradicionais famílias políticas, em suas lutas pelo poder no Paraná.

Como visto, é possível afirmar como uma das bases do poder local seria o de ser membro de uma família tradicional na região. Porém, quem eram as famílias mato-grossenses dos Ponce e Murtinho? Eram elas herdeiras das antigas sesmarias, descendentes de bandeirantes, de agentes do Estado, de militares, de mineradores? Ou apenas indivíduos isolados dotados de grandes 
habilidades e carismas, capazes de conduzir o processo político local? Acredita-se, a partir da leitura da obra da autora, na junção dos dois fatores, por existir uma continuidade na dominação por pertencerem a famílias políticas tradicionais, mas que seus herdeiros têm de assumir a responsabilidade de continuar a condução dos rumos de sua localidade, mantendo a posse de recursos territoriais, materiais ou de cargos públicos, impondo a conquista, assim como se deu no Brasil como um todo. Assim como afirma Ricardo Costa de Oliveira, o jogo político das continuidades é a marca das estruturas e da cultura política brasileira (Oliveira, in: GOULART, 2014, p.16), infelizmente.

E, ao contextualizar a chamada República Velha brasileira (1889-1930), a autora, a partir das obras de Edgard Carone, A República Velha (1970 e 1977), busca confirmar a existência de pequenos grupos, na qual chama de "elites locais" ou "grupos oligárquicos", que controlavam cada região do território nacional. Neste sentido, existiu a oligarquia paulista, formada pelo Partido Republicano; no Amazonas, pelos Nery; no Pará, pelos Montenegro; no Maranhão, por Benedito Leite; no Ceará, pela família Acióli; no Rio Grande do Norte, por Pedro Velho; em Pernambuco, pelos Rosa e Silva; no Rio de Janeiro, por Porciúncula e Nilo Peçanha; em Santa Catarina, por Lauro Müller; em Alagoas, pelos Malta; em Sergipe, pelo Padre Olímpio e pelo General Valadão; na Paraíba, por Venâncio Neiva e Epitácio Pessoa; no Mato Grosso (objeto de seu estudo), pelos Murtinho; e no Espírito Santo, por Jerônimo Monteiro (ARRUDA, 2015, p.16 e $139)^{2}$. Enfim, deve-se, como se observa, entender esses grupos oligárquicos no poder, entender essas famílias políticas, para se entender o Brasil como um todo.

Porém, em cada região, as oligarquias tinham de enfrentar seus rivais internos, o que, por sua vez, gerava conflitos entre as elites locais, cada qual querendo dominar o aparelho de Estado. Para o caso de Mato Grosso, na República Velha, "as oligarquias cuiabanas dominavam as demais oligarquias do grande território. O predomínio político estava com as famílias cuiabanas: Ponce, Murtinho, Corrêa da Costa e Paes de Barros" (ARRUDA, 2015, p.20).

\footnotetext{
${ }^{2}$ Apesar de Edgard Carone não citar o Paraná, pode-se dizer que esse estado era controlado, pós Proclamação da República, pelo grupo político liderado por Vicente Machado da Silva Lima, descendente de oligarquia familiar na região de Ponta Grossa, Paraná; em oposição a ele, o grupo político liderado por Generoso Marques dos Santos, descendente de famílias tradicionais de Curitiba, capital do Paraná. Mas quando necessário, frente a determinados interesses, ou inimigos comuns, acabavam unindo-se (GOULART, 2014), como foi os casos das "disputas oligárquicas" no Mato Grosso.
} 
Das quatro famílias citadas, foram um "elemento socioeconômico polarizador", de um lado, Generoso Ponce, e de outro Joaquim Murtinho. Nos anos abordados, as quatro famílias se compuseram das mais diversas formas, apenas foi constante a aliança entre Ponce e os Corrêa da Costa. Em um primeiro momento, estas oligarquias eram todas aliadas contra os militares. Após a vitória do grupo oligárquico, ocorreu sua divisão entre os Murtinho, aliados dos Paes de Barros, versus Ponce e os Corrêa da Costa. Ainda houve uma nova composição, as três famílias (Ponce, Corrêa da Costa e Murtinho) uniram-se contra o governador Antônio Paes de Barros, assassinado em 1906 (ARRUDA, 2015, p.20).

A autora, portanto, vai demonstrando como as quatro famílias articulavam o poder em Mato Grosso, durante o período de estudo, 1892 a 1906, unindo-se ou repelindo-se entre si, de acordo com os interesses e ganhos específicos. E, tendo como característica, as constantes lutas internas entre eles ou contra um inimigo externo, como os militares. A esses embates, muitas vezes violentos, Larissa Arruda denominou como "disputadas oligárquicas" (título de sua obra). As "disputas oligárquicas" em Mato Grosso ocorreram especialmente em três ocasiões, nos anos de 1892, 1899 e 1906, descritas especificamente no capítulo 2. As "disputas" ou até "revoluções", como chamaram outros autores, demonstram a violência com que as oligarquias lutavam pelo poder local no Estado, mobilizando amplas milícias particulares e envolvendo o próprio exército brasileiro. E, a vitória de um grupo significava o reforço da liderança de determinada oligarquia e de suas famílias. E, também, acompanhando o desenrolar factual de cada "disputa oligárquica", percebe-se o envolvimento dos demais coronéis aliados ou inimigos de Ponce ou de Murtinho. Por sua vez, à população, mesmo na República, cabia apenas receber as coerções impostas pelos grupos em confronto e esperar, nesse pacto coronelístico, como estes coronéis poderiam trazer benefícios à ainda débil economia mato-grossense. Era desses atores políticos que se dependia o desenvolvimento dessa região centro-oeste brasileira e o decorrente apoio do governo federal.

Nos capítulos 3 e 4, Larissa Arruda, então, descreve as oligarquias em ação e suas redes. Percebe-se, assim, a força política de cada uma delas e suas heranças.

Por exemplo, a família de Generoso Paes Leme de Souza Ponce chegou ao Mato Grosso em meados de 1700 atraídos pela descoberta de ouro na região. E, quanto ao próprio Generoso Ponce, entre os séculos XIX e XX, foi importante comerciante e político de grande influência sobre os demais coronéis locais. Tornou-se a principal liderança política desde o final do Império. A autora destaca, assim, a biografia de Generoso Ponce, devido sua centralidade na política matogrossense (Ibidem, p.157-163). Sua família vai continuando a atuar na política, como Júlio Strübing Müller casado com Maria de Arruda Müller (neta de Generoso Ponce) que foi interventor 
nomeado por Getúlio Vargas, de 1937 a 1945. Outro membro foi o político João Ponce de Arruda, cunhado de Júlio Müller. Inclusive, salienta Larissa Arruda, que "após 1911 [ano do falecimento de Generoso Ponce], a competição política ocorreu entre os Corrêa da Costa e os Ponce-Müller" (Ibidem, p.170), que foram aliados nas três "disputas oligárquicas".

O ouro também atraiu outra família paulista ao Mato Grosso, Paes de Barros, que se instalou em Cuiabá em 1731 (Ibidem, p.30); por exemplo, o govenador Antonio Paes de Barros, entre 1903 e 1906, que também foi senador, era filho do Barão de Piracicaba, Antonio Pais de Barros, descendente de mineradores no século XVIII e cafeicultores no século XIX em São Paulo. Entre 1999 a 2007 foi senador da República Antero Paes de Barros Neto. Portanto, uma família ainda ativa na política local e brasileira.

A família Murtinho era da Bahia, mas vem para o Mato Grosso com o médico e tenente José Antônio Murtinho, que se casou com a cuiabana Rosa Joaquina, filha do português e militar Joaquim Duarte Pinheiro. Durante o período imperial, José Antonio Murtinho foi nomeado Presidente da Província do Mato Grosso, entre 1868 a 1869, e seu filho Manuel José Murtinho foi nomeado Presidente da Província em 1889, depois, também, governador no período republicano em 1891-1892 e 1895. Outro filho, José Antonio Murtinho (Filho), médico, foi deputado federal e republicano histórico. Porém, o filho político mais influente foi o médico Joaquim Duarte Murtinho, que chegou a ser duas vezes Ministro de Estado, mas destacando-se como Ministro da Fazenda no Governo do Presidente Campos Salles (1898 a 1902), além de senador. Também, a autora dedica atenção especial à figura de Joaquim Murtinho, devido sua centralidade na política local e nacional, grande "empresário institucional" e médico homeopata de importantes políticos brasileiros (Ibidem, p.164-184). Apesar da família Murinho não participar mais da política (Ibidem, p.170), em especial com a morte de Joaquim, a autora cita a atuação do genro de Manoel Murtinho, Benedito Cipriano de Souza, durante as "disputas oligárquicas" (Ibidem, p.90). Enfim, como Joaquim Murtinho não casou, seria importante verificar os genros e descendentes dos outros dois irmãos políticos, Manoel e José Antonio Murtinho Filho, esse último chegou a ser senador pelo Mato Grosso de 1912 a 1930, eleito pós morte do irmão Joaquim em 1911. Manoel Murtinho foi membro do Supremo Tribunal Federal.

A quarta família em destaque é a Corrêa da Costa, também tradicional na região, sendo Antonio Corrêa da Costa nomeado várias vezes Presidente da Província do Mato Grosso em 1831, 1833/34, 1836, 1840, 1842/43. Seu filho Antonio Corrêa da Costa foi governador entre 1895 a 
1898, assim como seu irmão Pedro Celestino Corrêa da Costa, 1908 a 1911 e 1922 e 1923, e Mário Corrêa da Costa, entre 1926 a 1930 e 1935 a 1937. O primo Luís Adolfo foi senador. Fernando Corrêa da Costa, filho de Pedro Celestino, governou o Estado de 1951 a 1956 e 1961 a 1966. (Ibidem, p.144-145 e p.153-154).

A autora não deixa de "mapear" tantas outras famílias, muitas aparentadas entre si (Ibidem, p.153, nota 401), mas que, mesmo seus membros tornando-se senadores, deputados federais, estaduais, assumindo importantes cargos públicos no Estado, ao que se percebe, todos precisavam da anuência dos poderosos Ponce e Murtinho, donos igualmente dos partidos políticos republicanos locais.

Enfim, realizar de forma mais detalhada a genealogia dessas importantes famílias matogrossenses pode aprofundar a compreensão da força política de seus atores. E, de maneira geral, é claro que Generoso Ponce e Joaquim Murtinho literalmente mandavam no Mato Grosso, escolhendo candidatos para os principais cargos eletivos, ora juntos, ora separados, ora se enfrentando nas "disputas oligárquicas", ora unindo-se contra inimigos comuns.

Enfim, o livro de Larissa Arruda é riquíssimo em detalhes históricos possibilitando pensar a dinâmica da política local e sua essencial ligação com a política federal, no chamado pacto coronelista, contextualizando o que acontece em Mato Grosso e ao mesmo tempo descrevendo o que está a ocorrer no Rio de Janeiro, tendo como referências inúmeras fontes de época e interpretando criticamente autores que já tinham escrito sobre o período; um trabalho que discute igualmente o clássico conceito de coronelismo, de Victor Nunes Leal, além de outras importantes referências, como Maria Isaura Pereira de Queiroz. Dessa forma, todo esse grande trabalho de ciência política possibilita pensar no "mapeamento" dos arranjos e rearranjos das oligarquias, das famílias políticas, dos coronéis, tanto para os dias atuais, como também retroceder e pensar o período imperial e colonial no Mato Grosso. Rearranjos que levam a uma possível conclusão de que oligarquias com suas famílias políticas atravessam gerações no controle do poder, utilizando-se sempre do Estado.

\section{Referências Bibliográficas}


ARRUDA, Larissa Rodrigues Vacari de. Disputas oligárquicas: as práticas políticas das elites matogrossenses (1892-1906). Prefácio de Maria Teresa Miceli Kerbauy. São Carlos: EdUFSCar, 2015.

GOULART, Mônica Helena Harrich Silva. A Dança das Cadeiras: Análise do Jogo Político na Assembleia Legislativa do Paraná (1889-1930). Apresentação de Ricardo Costa de Oliveira. Jundiaí, Paco Editorial: 2014. 